\title{
Neutral Lipid Cacostasis Contributes to Disease Pathogenesis in Amyotrophic Lateral Sclerosis
}

\author{
James C. Dodge, ${ }^{1}$ Elizabeth H. Jensen, ${ }^{1}$ Jinlong Yu, ${ }^{1}$ S. Pablo Sardi, ${ }^{1}$ Allison R. Bialas, ${ }^{1}$ Tatyana V. Taksir, \\ ${ }^{-}$Dinesh S. Bangari, ${ }^{2}$ and Lamya S. Shihabuddin ${ }^{1}$ \\ ${ }^{1}$ Rare and Neurological Diseases Therapeutic Area, and ${ }^{2}$ Global Discovery Pathology, Sanofi R+D, Framingham, Massachusetts 01701
}

\begin{abstract}
Amyotrophic lateral sclerosis (ALS) is a fatal neuromuscular disease characterized by motor neuron (MN) death. Lipid dysregulation manifests during disease; however, it is unclear whether lipid homeostasis is adversely affected in the in the spinal cord gray matter (GM), and if so, whether it is because of an aberrant increase in lipid synthesis. Moreover, it is unknown whether lipid dysregulation contributes to MN death. Here, we show that cholesterol ester (CE) and triacylglycerol levels are elevated several-fold in the spinal cord GM of male sporadic ALS patients. Interestingly, HMG-CoA reductase, the rate-limiting enzyme in cholesterol synthesis, was reduced in the spinal cord GM of ALS patients. Increased cytosolic phospholipase A2 activity and lyso-phosphatidylcholine (Lyso-PC) levels in ALS patients suggest that CE accumulation was driven by acyl group transfer from PC to cholesterol. Notably, Lyso-PC, a byproduct of CE synthesis, was toxic to human MNs in vitro. Elevations in CE, triacylglycerol, and Lyso-PC were also found in the spinal cord of SOD1 ${ }^{\mathrm{G} 93 \mathrm{~A}}$ mice, a model of ALS. Similar to ALS patients, a compensatory downregulation of cholesterol synthesis occurred in the spinal cord of SOD1 ${ }^{\mathrm{G} 93 \mathrm{~A}}$ mice; levels of sterol regulatory element binding protein 2, a transcriptional regulator of cholesterol synthesis, progressively declined. Remarkably, overexpressing sterol regulatory element binding protein 2 in the spinal cord of normal mice to model CE accumulation led to ALS-like lipid pathology, MN death, astrogliosis, paralysis, and reduced survival. Thus, spinal cord lipid dysregulation in ALS likely contributes to neurodegeneration and developing therapies to restore lipid homeostasis may lead to a treatment for ALS.
\end{abstract}

Key words: amyotrophic lateral sclerosis; motor neuron disease

Significance Statement

Neurons that control muscular function progressively degenerate in patients with amyotrophic lateral sclerosis (ALS). Lipid dysregulation is a feature of ALS; however, it is unclear whether disrupted lipid homeostasis (i.e., lipid cacostasis) occurs proximal to degenerating neurons in the spinal cord, what causes it, and whether it contributes to neurodegeneration. Here we show that lipid cacostasis occurs in the spinal cord gray matter of ALS patients. Lipid accumulation was not associated with an aberrant increase in synthesis or reduced hydrolysis, as enzymatic and transcriptional regulators of lipid synthesis were downregulated during disease. Last, we demonstrated that genetic induction of lipid cacostasis in the CNS of normal mice was associated with ALS-like lipid pathology, astrogliosis, neurodegeneration, and clinical features of ALS.

Received June 2, 2020; revised July 31, 2020; accepted Aug. 28, 2020.

Author contributions: J.C.D. designed research; J.C.D., E.H.J., J.Y., A.R.B., and T.V.T. performed research;

J.C.D., E.H.J., T.V.T., D.S.B., and L.S.S. analyzed data; J.C.D. wrote the first draft of the paper; J.C.D., E.H.J.,

S.P.S., A.R.B., T.V.T., D.S.B., and L.S.S. edited the paper; J.C.D. wrote the paper; S.P.S. contributed unpublished

reagents/analytic tools.

All authors are employees of Sanofi.

Human tissue was obtained from National Institute of Child Health and Human Development Brain and Tissue Bank for Developmental Disorders at the University of Maryland (Baltimore; Contract HHSN275200900011C, Reference N01-HD-9-0011). We thank Channa Bao, Thomas Tamsett, Marissa Abraham, and Christopher Treleaven for technical assistance; and Dr. Rita-Balice Gordon for feedback.

Correspondence should be addressed to James C. Dodge at james.dodge@sanofi.com.

https://doi.org/10.1523/JNEUROSCI.1388-20.2020

Copyright $\odot 2020$ the authors

\section{Introduction}

Amyotrophic lateral sclerosis (ALS) is a progressive paralytic neuromuscular disorder characterized by the degeneration of motor neurons (MNs) in the brain and spinal cord. Several lines of evidence suggest that lipid dysregulation contributes to disease pathogenesis in ALS. Notably, several genes implicated in ALS (e.g., ANG, C9ORF72, HNRNPA1, SIGMAR1, SOD1, TARDBP, VAPB, and VCP) and modifiers of disease progression (e.g., ATXN2 and liver $\mathrm{X}$ receptor [LXR]) are significant modulators of lipid homeostasis (Moore and Riordan, 1990; Lastres-Becker et al., 2008; Chiang et al., 2010; Su et al., 2010; Morris et al., 2014; Yu et al., 2014; Li et al., 2015; Sanhueza et al., 2015; Tokutake et al., 2015; Mouzat et al., 2018; Liu and Wang, 2019). In addition, disrupted lipid metabolism (i.e., lipid cacostasis) occurs in the 
spinal cord during aging (Parkinson et al., 2016), a risk factor for developing ALS. Furthermore, cholesterol ester (CE) accumulation is observed in whole spinal cord tissue homogenates of sporadic ALS patients and in rodent models of ALS (Cutler et al., 2002; Chaves-Filho et al., 2019), and total cholesterol levels are elevated in the CSF of ALS patients (Abdel-Khalik et al., 2017). And last, dyslipidemia and altered apolipoprotein metabolism in blood are risk factors for ALS, and are also prognostic indicators of disease progression in ALS patients (Dupuis et al., 2008; Dorst et al., 2011; Mariosa et al., 2017; Chen et al., 2018). Although it is evident that lipid cacostasis manifests during ALS, it is still unclear whether it occurs in the region of the spinal cord where MNs degenerate, specifically the ventral gray matter (GM), and if so, what causes it. Potential triggers of lipid accumulation include an aberrant increase in lipid synthesis, a reduction in hydrolysis, or an impairment in lipid transport. Finally, it is unknown whether lipid cacostasis in the spinal cord contributes to $\mathrm{MN}$ death or whether it is just a consequence.

In the adult CNS, cholesterol synthesis occurs primarily in astrocytes (Nieweg et al., 2009) and is regulated by the transcription factor sterol regulatory element binding protein-2 (SREBP2), which also plays a more limited role in modulating fatty acid, triacylglycerol (TAG), and phospholipid levels (Horton et al., 1998). Interestingly, in human fibroblasts, the expression of SREBP2 and HMG-CoA reductase (HMGCR), the rate-limiting enzyme in cholesterol synthesis, is inhibited by SOD1 independently of its dismutase activity (Mondola et al., 2002; De Felice et al., 2004). This is intriguing because SOD1-related ALS purportedly arises through a toxic property of the mutant enzyme rather than through a change in dismutase activity (Borchelt et al., 1994, 1995). Whether or not mutant SOD1 adversely affects the proteolytic processing of SREBP2 to induce an aberrant increase in lipid synthesis, and subsequently $\mathrm{MN}$ degeneration, remains unknown.

Here we show that CEs, TAG, and lysophosphatidylcholine (Lyso-PC), a byproduct of CE synthesis, are significantly elevated in the spinal of sporadic ALS patients, especially in the GM. Similar progressive changes in neutral lipids were also observed in the spinal cords of SOD $1^{\mathrm{G} 93 \mathrm{~A}}$ mice, a familial mouse model of ALS. Notably, we also found that specific isoforms of Lyso-PC were toxic to human MNs in vitro. Interestingly, SREBP2 and HMGCR, transcriptional and enzymatic initiators of de novo cholesterol synthesis, were reduced in the spinal cords of ALS patients and SOD1 ${ }^{\mathrm{G} 93 \mathrm{~A}}$ mice, whereas enzymes that promote lipid hydrolysis were upregulated during disease. Finally, we show that increasing SREBP2 in the CNS of WT mice resulted in ALS-like neutral lipid accumulation and the development of a robust ALS disease phenotype featuring astrogliosis, $\mathrm{MN}$ degeneration, muscular atrophy, paralysis, and a reduced lifespan. These findings suggest that disease-associated neutral lipid accumulation in the spinal cord likely contributes to $\mathrm{MN}$ death and that restoring lipid metabolism to its optimal homeostatic state may lead to a disease-modifying treatment for ALS.

\section{Materials and Methods}

Human tissue samples. Cervical spinal cord segments from 6 male patients who died of respiratory failure caused by advanced ALS were used in our analyses. Control samples were obtained from 7 agematched male individuals without evidence of neurologic disease. Human tissue was obtained from the National Institute of Child Health and Human Development Brain and Tissue Bank for Developmental Disorders at the University of Maryland (Contract HHSN275200900011C, Reference N01-HD-9-0011).
Animals. Transgenic male ALS mice that express the mutant SOD $1^{\text {G93A }}$ transgene at high levels (B6SJL background strain) were divided equally among groups. Mutant $\mathrm{SOD} 1^{\mathrm{G} 93 \mathrm{~A}}$ gene copy number and protein expression were confirmed by PCR and Western blot analysis, respectively. Animals were housed under light:dark (12:12 h) cycles and provided with food and water ad libitum. At $75 \mathrm{~d}$ of age, food pellets were place on the cage floor to facilitate access and consumption. Mice were scored daily into the following phases: symptomatic (SYMP; median age of $82 \mathrm{~d}$ ) = abnormal hindlimb splay; end stage (ES; median age of $103 \mathrm{~d}$ ) = onset of limb paralysis (typically hindlimb); and moribund $(\mathrm{MB}$; median age of $122 \mathrm{~d})=$ unable to right themselves within $30 \mathrm{~s}$ after being placed on their backs. WT mice used in adenovirus-associated virus (AAV) gene transfer studies were generated from B6SJL breed pairs. All samples taken from mice were collected between 9:45 A.M. and 10:15 A.M. unless stated otherwise to avoid variation because of circadian fluctuations in metabolism. All procedures were performed using protocols approved by Sanofi Genzyme's Institutional Animal Care and Use Committees.

Experimental design and statistics. The experimental design for each assay is described in its subsection below. Normality was determined using the Shapiro-Wilk normality test. Datasets that failed the normality test were analyzed with a Mann-Whitney test. A two-tailed unpaired $t$ test was used to compare datasets that passed the normality test and that had equal variances. If dataset variances were significantly different, then an unpaired $t$ test with Welch's correction was used to compare groups that passed the normality test. Statistical tests comparing multiple groups were performed using either a one-way or two-way ANOVA followed by a Dunnett's multiple comparison post hoc test to find differences between group means. Survival analysis was conducted by the Kaplan-Meier method. A value of $p<0.05$ was considered statistically significant. All statistical tests were performed using GraphPad Prism Software 7.0.

Lipid analysis. CE, triacylglyceride, and phospholipid analysis of human and mouse spinal cord samples was conducted by Metabolon. For human samples, grey matter (GM) and ventral white matter (VWM) tissue segments from the cervical spinal cord were analyzed separately ( $n=6$ or $7 /$ tissue type/group). In mouse experiments, whole lumbar spinal cords were used ( $n=8-10$ /group). Briefly, lipids were extracted from spinal cord samples $(35-50 \mathrm{mg}$ ) in methanol:dichloromethane in the presence of internal standards. Sample extracts concentrated under nitrogen and reconstituted in $0.25 \mathrm{ml}$ of $10 \mathrm{~mm}$ ammonium acetate dichloromethane:methanol (50:50) were transferred to inserts and placed in vials for infusion-MS analysis, performed on a Shimazdu LC with nano PEEK tubing and the Sciex SelexIon-5500 QTRAP. The samples were analyzed via both positive and negative mode with electrospray ionization. Individual lipid species were quantified by taking the peak area ratios of target compounds and their assigned internal standards, then multiplying by the concentration of internal standard added to the sample.

Measurement of cholesterol and its precursors, lanosterol, desmosterol, and 24,25 dihydrolanosterol (24DHLan), was performed by Biocrates Life Sciences AG. Sample homogenates were prepared by Dounce homogenizing (20 strokes) human cervical spinal cord tissue GM and VWM tissue ( $n=6$ or $7 /$ tissue type/group), mouse lumbar spinal cord tissue ( $n=5 /$ group), and mouse feces ( $25 \mathrm{mg} ; n=5 /$ group) samples in the following buffer $(20 \times \mathrm{vol} /$ weight $): 10 \mathrm{~mm}$ HEPES, $10 \mathrm{~mm}$ $\mathrm{NaCl}, 1 \mathrm{~mm} \mathrm{KH} \mathrm{KO}_{4}, 5 \mathrm{~mm} \mathrm{NaHCO}$, 5 mu EDTA, $1 \mathrm{mM} \mathrm{CaCl}_{2}$, and 0.5 $\mathrm{mM} \mathrm{MgCl}$. Homogenates were placed on ice for $10 \mathrm{~min}$ and then centrifuged at $6300 \times g$ at $4^{\circ} \mathrm{C}$ for $10 \mathrm{~min}$. Cholesterol analytes were extracted from the tissue homogenate supernatants, mouse plasma (100 $\mu \mathrm{l} ; n=5$ / group), and mouse serum ( $100 \mu \mathrm{l} ; n=5$ /group) with methanol using the BIOCRATES Kit filter plate, which was preloaded with an internal standard mixture. The extract was then subjected to alkaline hydrolysis to release oxysterols from their respective esters. After neutralization, the metabolites were determined by UHPLC-tandem mass spectrometry with Multiple Reaction Monitoring in positive mode using a SCIEX API QTRAP 5500 mass spectrometer with electrospray ionization.

Enzyme activity assays. Tissue homogenates were prepared by Dounce homogenizing human GM and VWM cervical spinal cord segments ( $n=6$ or $7 /$ tissue type/group) in an ice-cold buffer $(10 \mathrm{ml} / \mathrm{g}$ tissue; 
50 mм HEPES, 1 mм EDTA, pH 7.4). Homogenates were centrifuged at $10,000 \times g$ for $15 \mathrm{~min}$ at $4^{\circ} \mathrm{C}$. Supernatants were removed and then analyzed for lipoprotein lipase (item \#STA-610; Cell Bio Labs) and cytosolic phospholipase A2 (item \#765021, Cayman Chemical) enzyme activities using assay kits according to the manufacturer's directions.

qRT-PCR. Total RNA was extracted with Ambion MagMAX-96 RNA isolation kit (Applied Biosystems) from the lumbar spinal cords of mice ( $N=8$-14/group), reverse-transcribed, amplified with TaqMan One-Step RT-PCR Master Mix Kit (Applied Biosystems), and analyzed on an ABI PRISM 7500 Real-Time PCR System (Applied Biosystems). Primer probes purchased from Thermo Fisher Scientific were used to quantify the expression levels for SREBP2 (Mm01306292_m1), lysosomal acid lipase (LIPA) (Mm01204979_ml), hormone-sensitive lipase (LIPE) (Mm00495359_ml), LIPC (Mm00433975_m1), lipoprotein lipase (LPL) (Mm00434764_m1), DHCR24 (Mm00519071_m1), DHCR7(Mm00514571_m1), acyl-CoA cholesterol acyltransferase (SOAT1) (Mm00486279_m1), cytosolic phospholipase A2 (cPLA2)/Pla2g4a (Mm00447040_m1), lecithin:cholesterol acyltransferase (LCAT) (Mm00500505_m1), microsomal triglyceride transfer protein (MTTP) (Mm00435015_m1), ABCA1 (Mm00442646_m1), ABCG1 (Mm00437390_m1), CAV1(Mm00483057_m1), CAV2 (Mm00516827_m1), and CEL (Mm00486981_m1). Expression analysis was normalized to PPIA (Mm02342430_g1) mRNA levels.

$A A V$ vectors. The open reading frame of the human SREBP2 CDNA (NCBI accession number NP_004590.2) was cloned into a shuttle plasmid containing the AAV2 inverted terminal repeats and the $1.6 \mathrm{~kb}$ cytomegalovirus enhancer/chicken $\beta$-actin (CBA) promoter. The plasmid, which expressed constitutively active human SREBP2 under the CBA promoter, was packaged into AAV serotype 9 capsid by triple-plasmid cotransfection of HEK293T cells, and virions were column purified as previously reported (Rabinowitz et al., 2002). As a control vector, the hSREBP2 cDNA was replaced with a stuffer sequence to generate AAV2/9-CBA-null (AAV9-null). The resulting vectors, AAV2/9-CBAhSREBP2 (AAV9-SREBP2) and AAV9-null possessed titers of $8.3 \times 10^{12}$ genome copies $/ \mathrm{ml}$ and $1.2 \times 10^{13}$ genome copies $/ \mathrm{ml}$, respectively.

CNS injection of $A A V$ vectors. On the day of birth (P0), BS6SJL mouse pups received three injections of $2 \mu \mathrm{l}$ each into the cerebral lateral ventricles of both hemispheres and the upper lumbar spinal cord. The AAV9-SREBP2 vectors were injected at full strength, and thus the total dose was $5.0 \times 10^{10}$ genome copies. The AAV9-null vector was diluted with saline to titer match the AAV9-SREBP2 dose. All the injections were performed with a finely drawn glass micropipette needle as previously described (Passini et al., 2003). Following the injections, the pups were toe clipped to identify which pups were treated with AAV9SREBP2.

SREBP2 Western blots. Lumbar spinal cords were dissected from PBS-perfused SOD1 ${ }^{\mathrm{G} 93 \mathrm{~A}}$ mice at different disease phases $(N=6 /$ disease phase) and WT control $(N=6)$ for analysis. In the AAV studies, lumbar spinal cords were collected from PBS-perfused MB AAV-SREBP2treated mice $(N=5)$, mice with significant $\mathrm{MN}$ death, and age-matched sibling controls treated with AAV-null $(N=5)$. For human samples, GM and VWM tissue segments from the cervical spinal cord were analyzed separately ( $n=6$ or $7 /$ tissue type/group). Tissues were homogenized at a final concentration of $50 \mathrm{mg}$ protein/ml using T-Per lysis buffer and protease inhibitor cocktail (Pierce). The homogenates were cleared by centrifugation, and the protein concentration was measured by BCA assay (Pierce); $10-20 \mu \mathrm{g}$ of homogenate protein was resolved on a $4 \%-12 \%$ SDS-PAGE, transferred to nitrocellulose membrane, and probed with rabbit polyclonal anti-SREBP2 (1:100; Ab30682), rabbit monoclonal anti-HMGCR mouse (1:500, Ab174830), and monoclonal anti- $\beta$-tubulin (1:5000; Ab7291) antibodies purchased from Abcam. The membranes were incubated with infrared secondary antibodies (1:20,000; LI-COR Biosciences), and protein bands were visualized by quantitative fluorescence using Odyssey software (LI-COR Biosciences). Molecular weight markers confirmed the sizes of the bands.

ABCA1 Western blots. ES SOD1 and WT mice ( $N=5$ /group) were perfused with cold $1 \times \mathrm{PBS}, \mathrm{pH} 7.4$; the lumbar spinal cords were removed, flash frozen, and stored at $-8^{\circ} \mathrm{C}$. Then, lumbar spinal cord tissue was lysed in $2 \%$ SDS in $10 \mathrm{~mm}$ HEPES, pH 7.4. After BCA protein quantification (Thermo Scientific 23225), $100 \mu$ g protein per sample was chloroform/methanol precipitated and air-dried. Next, the samples were deglycosylated with rapid PNGase F (NEB, P0710S) in the two-step protocol according to the manufacturer's instructions and speed-vacuumed until dry. Then, the samples were resuspended in $1 \times$ loading dye (NP0007) and loaded onto a Tris-acetate 3\%-8\% $1.0 \mathrm{~mm}$ NuPAGE gel (EA03755BOX) with Chameleon Duo Prestained Protein Ladder (Li-COR, 928-60000) and run in $1 \times$ NuPAGE Tris-Acetate Running Buffer (LA0041). Then, the gel was transferred to the Invitrolon PVDF membrane (LC2005) in 1× Tris-glycine transfer buffer (Bio-Rad, 1610734) on ice. At room temperature, the membrane was blocked for $1 \mathrm{~h}$ in Li-COR PBS blocking buffer (Li-COR, 927-40000) diluted 1:1 in $1 \times$ PBS and then for $1.5 \mathrm{~h}$ in the following primary and secondary antibodies diluted in blocking buffer: rabbit polyclonal Abcal antibody (Novus, NB400-105, 1:125), mouse monoclonal $\alpha$-tubulin (Sigma Millipore, T9026, 1:1000), mouse monoclonal $800 \mathrm{~nm}$ secondary antibody (Rockland, 1:10,000), and rabbit monoclonal $680 \mathrm{~nm}$ secondary antibody (Rockland, 1:10,000). The membrane was imaged on the LiCOR Odyssey and blot intensities quantified on the Li-COR Image Studio software. Reported levels are normalized first to loading controls and then to the average normalized WT levels. All reagents are from Thermo Fisher Scientific unless otherwise stated.

Immunohistochemistry and MN quantification. For histologic analysis, mice ( $N=4$ /group) were perfused with $4 \%$ PFA, $\mathrm{pH} 7.4$; the spinal cords were removed and placed in 30\% sucrose for $48-72 \mathrm{~h}$, embedded in OCT, and cut into $10 \mu \mathrm{m}$ frozen sections with a cryostat. To visualize MNs spinal cord sections were blocked for $1 \mathrm{~h}$ at room temperature and then incubated with a goat polyclonal anti-ChAT antibody (Millipore AB144PMI; 1:100 dilution) for $1 \mathrm{~h}$ at room temperature followed by an overnight incubation at $4^{\circ} \mathrm{C}$ in a humidified chamber to identify MNs. Spinal cord sections were then incubated for $1 \mathrm{~h}$ at room temperature with a biotinylated anti-mouse, Cy3-conjugated anti-goat secondary antibody (1:250 dilution; Jackson ImmunoResearch Laboratories). To increase ChAT-immunopositive signal, a TSA signal amplification kit (PerkinElmer) was used according to the manufacturers' instructions. The number of ChAT-immunopositive cells were counted on $10 \mu \mathrm{m}$ coronal lumbar spinal cord tissue sections. Cells located in laminae 8 and 9 (ventral horn) of the spinal cord that exhibited a fluorescent ChAT signal were considered MNs. Approximately 8-10 different levels were counted to generate the overall average number of $\mathrm{MN}$ counts per lumbar spinal cord segment for each animal. To prevent double counting of the same cell, each section was at least $100 \mu \mathrm{m}$ apart. Special care was also taken to compare anatomically matched sections between different animals, and cell counts were collected and recorded by a blinded observer. For ChAT and GFAP double staining, spinal cord slices mounted onto slides were first washed in $1 \times$ KPBS $(0.1 \mathrm{M}$ potassium phosphate buffer, $\mathrm{pH}$ 8.0). Then, the slides were boiled for $20 \mathrm{~min}$ in $1 \times$ citrate buffer, pH 6.0 (1:100 in water, Jackson ImmunoResearch Laboratories, H3300), acclimated to room temperature, rinsed in $1 \times$ KPBS, and placed in blocking buffer (5\% normal donkey serum, Jackson ImmunoResearch Laboratories, $017-000-121,0.25 \%$ Triton X-100 in $1 \times$ KPBS) for $1 \mathrm{~h}$ at room temperature. Next, the slides were incubated in 1:100 ChAT antibody and 1:200 GFAP monoclonal rat antibody (Thermo Fisher Scientific, 13-0300) in blocking buffer (5\% normal donkey serum, $0.2 \%$ Triton X-100 in $1 \times$ KPBS) for $1.5 \mathrm{~h}$ at room temperature and then overnight for $2 \mathrm{~d}$ at $4^{\circ} \mathrm{C}$ in a humidified chamber. Next, the slides were rinsed 3 times with $1 \times \mathrm{KPBS}$ and then incubated in 1:250 secondary antibodies (Donkey anti-goat AlexaFluor-488, Donkey antirat AlexaFluor-594, Thermo Fisher Scientific) for $1 \mathrm{~h}$. Then, the slides were rinsed 3 times with $1 \times$ KPBS and coverslipped with Vectashield with DAPI (Vector Labs). The slides were imaged using the confocal microscope (Leica Microsystems) and then images exported in Fiji version 1.5 .

Oil Red O staining. Fixed frozen spinal cord sections were brought to room temperature and then immersed in deionized water for $2 \mathrm{~min}$. A working solution of Oil Red $\mathrm{O}$ was prepared by combining $60 \mathrm{ml}$ of a stock solution ( $0.5 \mathrm{~g}$ Oil Red O in isopropyl alcohol) and $40 \mathrm{ml}$ of $1 \%$ dextrin solution. Slides were then placed in a filtered working solution of $0.5 \%$ Oil Red O in dextrin for $20 \mathrm{~min}$ and then rinsed very gently in running tap water. Finally, slides were counterstained with alum 
hematoxylin for $20 \mathrm{~s}$, gently rinsed with water, and then coverslipped with aqueous mounting media.

Lean and fat mass composition measurements. Lean and fat mass in ALS mice (as a function of disease stage) and age-matched WT counterparts were measured with an EchoMRI-100 (EchoMRI) according to the manufacturer's instructions. Measurements were conducted on living, nonsedated mice in $<1 \mathrm{~min}$.

Human MN viability studies. Experiments were conducted by BrainXell using human iPSC-derived MNs from a normal control patient (WC-30line). The culture medium was composed of a 1:1 mixture of Neurobasal Medium (Invitrogen, \#21103-049) and DMEM/F12 Medium (Invitrogen, \#11330-032) supplemented with the following: 1× B27 Supplement (Invitrogen, \#17504-044), 1× N2 Supplement (Invitrogen, \#17502-048), 0.5 mM GlutaMAX (Invitrogen, \#35050-061), $15 \mu \mathrm{g} / \mathrm{ml}$ Geltrex (Invitrogen, \#A1413201), $200 \mu \mathrm{M}$ ascorbic acid, $10 \mathrm{ng} /$ $\mathrm{ml}$ BDNF (Peprotech, \#450-02), and 1× BrainXell Motor Neuron Supplement. Neurons were seeded (day 0) at $100 \mu \mathrm{l} /$ well onto whitewalled, clear-bottom, PDL-coated 96-well plates (Greiner Bio-One, \#655944) at a concentration of 10,000 neurons/well. After seeding, plates were placed in a humidified chamber inside a standard cell culture incubator with $5 \% \mathrm{CO}_{2}$ at $37^{\circ} \mathrm{C}$. On day $7,10 \mu \mathrm{l}$ of the corresponding treatment solution (at $20 \times$ the final concentration) was added to each well. For the negative control condition ("vehicle"), medium alone was added. An additional $90 \mu \mathrm{l}$ of fresh culture medium was then added to all wells to reach a final volume of $200 \mu \mathrm{l} /$ well. Each treatment was tested in triplicate in an 8 point dose-dependent manner. On day 10 , the plates in each respective group were processed to determine ATP concentration using CellTiter-Glo 2.0 assay (Promega, G9242) according to the manufacturer's protocol. All plates and reagents were brought to room temperature before beginning the assay. First, $100 \mu \mathrm{l}$ of medium was gently removed from each well. Next, $100 \mu \mathrm{l}$ of the CellTiter-Glo buffer/luciferase solution was added to the wells. After 2 min of shaking at $300 \mathrm{rpm}$ and $10 \mathrm{~min}$ of stabilization, the relative luminescence signal was measured using a plate reader (Tecan). Plates were processed in a staggered manner to eliminate any differences in assay timing. The release of lactate dehydrogenase $(\mathrm{LDH})$ into the culture medium was also measured on day 10. LDH is normally present only in small amounts in the culture medium but increases in concentration when released from dead or dying cells. The LDH concentration was measured according to the manufacturer's protocol (Lactate Dehydrogenase Activity Assay Kit, Sigma Millipore, \#MAK066-1KT). Briefly, $50 \mu \mathrm{l}$ of culture medium (supernatant) was gently removed from each well and then transferred to a new clear-bottom plate. Assay reagents were then added to reach a final volume of $100 \mu \mathrm{l}$. The plates were incubated at $37^{\circ} \mathrm{C}$ in an incubator for $30 \mathrm{~min}$. The absorbance signal at $485 \mathrm{~nm}$, which was proportional to the LDH concentration, was then measured using a plate reader (Tecan).

\section{Results}

\section{Neutral lipids accumulate in the spinal cord GM of ALS patients}

We used mass spectrometry to examine cervical spinal tissue samples collected at autopsy from ALS patients and age-matched controls for region-specific changes in lipids. In contrast to an earlier study that examined $\mathrm{C}_{16}$ and $\mathrm{C}_{18} \mathrm{CE}$ species in the whole spinal cord (Cutler et al., 2002), we analyzed GM and ventral white matter (VWM) samples separately for saturated (SFA), monounsaturated (MUFA) and polyunsaturated (PUFA) species of $\mathrm{CE}$ and triacylglyceride (TAG). Similar analyses were conducted on whole lumbar spinal cords collected from $\mathrm{SOD} 1{ }^{\mathrm{G} 93 \mathrm{~A}}$ mice at different stages of disease and their WT counterparts. Several SFA $\left(\mathrm{C}_{14}, \mathrm{C}_{16}, \mathrm{C}_{18}\right)$, MUFA $\left(\mathrm{C}_{16: 1 \mathrm{nn}}, \mathrm{C}_{18: \ln 7}, \mathrm{C}_{18: 1 \mathrm{n} 9}\right)$, and PUFA $\left(\mathrm{C}_{18: 2 \mathrm{n} 6}, \mathrm{C}_{20: 3 \mathrm{n} 6}, \mathrm{C}_{20: 4 \mathrm{n} 6}\right)$ species of $\mathrm{CE}$ were elevated up to 22-fold in ALS patient samples. ALS-related changes in CE were most pronounced in the GM of the spinal cord but also occurred in the VWM (Fig. 1a). Significant progressive increases (up to fourfold $)$ in $C E$ species $\left(\mathrm{C}_{18: \ln 7}, \mathrm{C}_{18: \ln 9}\right.$, and $\left.\mathrm{C}_{18: 2 n 6}\right)$ were also detected in the spinal cords of ES and MB SOD $1{ }^{\mathrm{G} 93 \mathrm{~A}}$ mice (Fig. $1 b$ ). For TAG, $C_{16}$, and $C_{18: \ln 9}$, species were increased up to threefold in ALS patients (Fig. 1c). Similar significant changes in TAG $\mathrm{C}_{18: \ln 9}$ were detected in MB SOD $1{ }^{\mathrm{G} 93 \AA}$ mice (Fig. 1d). In SOD $1{ }^{\mathrm{G} 93 \mathrm{~A}}$ mice, positive Oil Red O staining, a marker of neutral lipids, including CE and TAG, progressively increased in the spinal cord central canal and white matter during disease course (Fig. 1e,f). Collectively, our results confirm that spinal cord lipid dysregulation is a feature of ALS and show, for the first time, that it manifests predominantly in the GM.

\section{Neutral lipid accumulation in ALS is not because of increased lipid synthesis or impaired hydrolysis}

Next, we determined whether spinal cord lipid accumulation in ALS was associated with disease-related changes in lipid synthesis or hydrolysis. First, we measured SREBP2, the master transcriptional regulator of cholesterol synthesis, in the spinal cords of ALS patients and SOD1 ${ }^{\mathrm{G} 93 \mathrm{~A}}$ mice to determine whether SREBP2 activity was aberrantly elevated during disease. Recently, it was reported in late stage SOD $1{ }^{\mathrm{G} 93 \mathrm{~A}}$ mice that SREBP2 staining was increased in astrocytes and MNs in the spinal cord (Baker et al., 2015). This observation raises the possibility that CE accumulation may be a consequence of increased in cholesterol synthesis driven by SREBP2 (Fig. 2a). Interpretation of these findings, however, is limited because quantification of the transcriptionally active form of SREBP2 was not assessed in the former experiment. Here, we measured SREBP2 mRNA levels in SOD1 ${ }^{\mathrm{G} 93 \mathrm{~A}}$ mice, and the membrane bound precursor (125 $\mathrm{kDa})$, and the transcriptionally active $(60-70 \mathrm{kDa})$ forms of SREBP2 protein in the spinal cords of SOD $1^{\mathrm{G} 93 \mathrm{~A}}$ mice and ALS patients. Notably, SYMP and ES SOD $1^{\mathrm{G} 93 \mathrm{~A}}$ mice showed significant reductions in SREBP2 $\mathrm{mRNA}$ and robust declines $(-51 \%$ and $-74 \%$ ) in transcriptionally active SREBP2 compared with WT controls (Fig. $2 b$; Extended Data Fig. 2-1). SREBP2 protein levels were not altered in the GM and VWM cervical spinal cord tissue samples of ALS patients (Extended Data Fig. 2-2). However, HMGCR, an enzyme upregulated by SREBP2 activity and the rate-limiting enzyme in cholesterol synthesis, was significantly reduced in the spinal cord GM of ALS patients (Fig. 2c). Although reductions in SREBP2 and HMGCR were observed, free cholesterol (FC) levels were not altered in the spinal cords of ALS patients or SOD ${ }^{\mathrm{G} 93 \mathrm{~A}}$ mice (Extended Data Fig. 2-3). This was not unexpected because our analysis was limited to measuring FC levels in whole tissue homogenates. Measurement of FC in the endoplasmic reticulum of specific cell types may lead to the detection of disease-related reductions in FC synthesis. In contrast to FC, we did find that lanosterol and desmosterol, precursors to cholesterol, and DHCR7 and DHCR24, enzymes that convert 7-dihydrocholesterol and desmosterol to cholesterol, respectively (Fig. $2 a$ ), were significantly altered in the spinal cords of ES SOD $1{ }^{\mathrm{G} 93 \mathrm{~A}}$ mice versus WT counterparts (Fig. $2 d$ ). These changes were consistent with a downregulation in SREBP2 and de novo cholesterol synthesis. Interestingly, 24DHLan, an endogenous inhibitor of HMGCR, was elevated in the spinal cords of SOD ${ }^{\mathrm{G} 93 \mathrm{~A}}$ mice (Fig. 2e). In ALS patients, lanosterol was also significantly reduced in the spinal cord (Fig. 2f); however, 24DHLan and desmosterol were not altered (Extended Data Fig. 2-4). TAG accumulation was also not associated with an aberrant increase in synthesis. The expression of diglyceride acyltransferase 1 and 2 (DGAT1, DGAT2), enzymes that catalyze the formation of TAG from diacylglyceride (DAG) and acyl-CoA, were not altered by disease in the spinal cords of SOD $1^{\mathrm{G} 93 \mathrm{~A}}$ mice (Extended Data Fig. 2-5). 
a

CTRL-GM ALS-GM

므. CTRL-WWM a ALS. WwM

SFA Cholesterol Esters
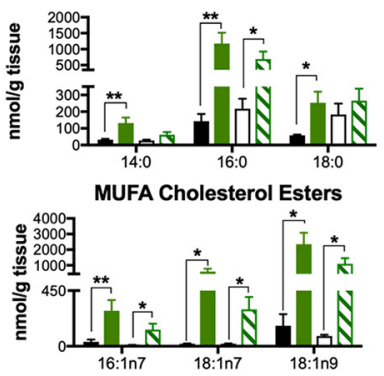

PUFA Cholesterol Esters

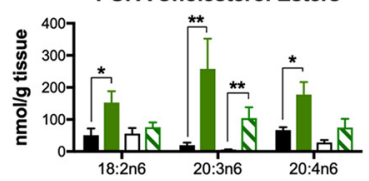

b
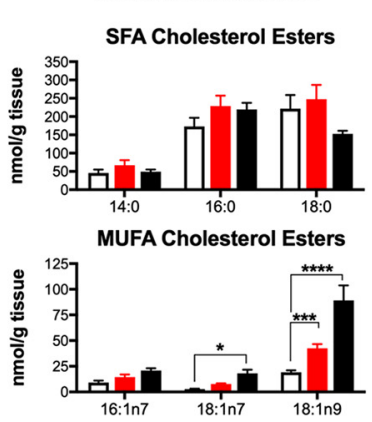

PUFA Cholesterol Esters

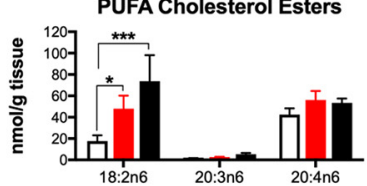

C

CTRL-GM ALS -GM 다RL-VWM ALS-VWM

SFA TAG
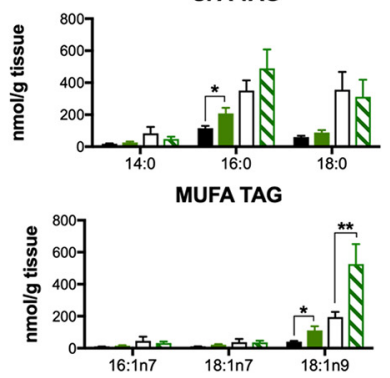

PUFA TAG

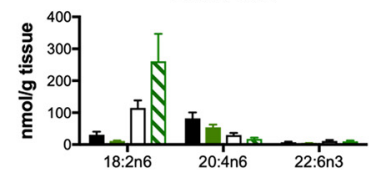

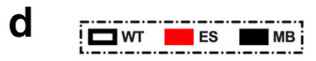

SFA TAG
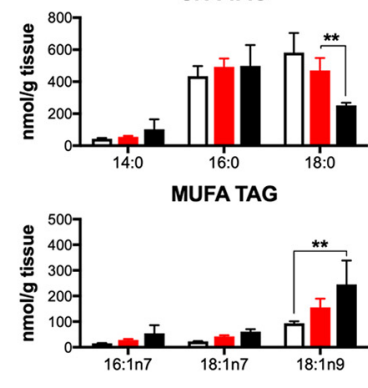

PUFA TAG

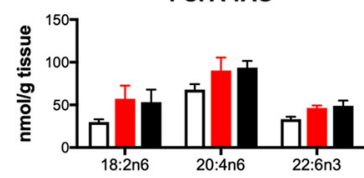

\section{e}
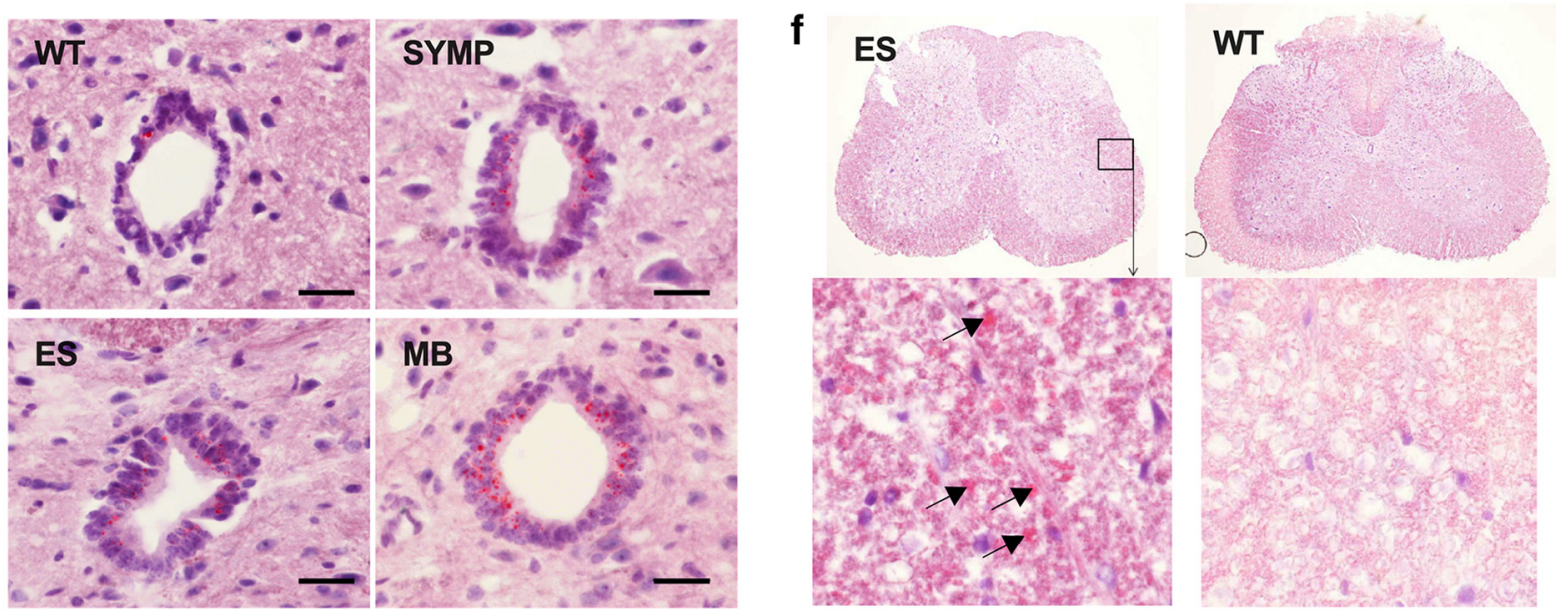

Figure 1. Neutral lipids accumulate in the spinal cords of ALS patients and SOD1 ${ }^{693 A}$ mice. Changes in SFA, MUFA, and PUFA species of $(\boldsymbol{a}, \boldsymbol{b})$ CEs and $(\boldsymbol{c}, \boldsymbol{d})$ triacylglycerides (TAG) in cervical spinal cord homogenates of ALS patients, and in lumbar spinal cord tissue homogenates of SOD1 ${ }^{693 A}$ mice with a clinical score of ES or MB. $e$, Oil Red 0 staining in the lumbar spinal cord central canal of SYMP, ES, and MB SOD1 ${ }^{693 A}$ mice and WT mice. $f$, Oil red 0 staining in the VWM of ES SOD1 ${ }^{693 A}$ and WT mice. Statistical comparisons for patient data are relative to age-matched control (CTRL) tissue subtype and SOD1 ${ }^{693 A}$ mice are compared with WT controls. ${ }^{* * * *} p=0.0001,{ }^{* * *} p=0.001,{ }^{* *} p=0.01,{ }^{*} p=0.05$. Columns not connected by the same letter are significantly $(p=0.001)$ different from each other. Error bars indicate SEM.

CE and TAG accumulation could also potentially be because of reduced lipid hydrolysis. The results of current experiments, however, do not support this supposition. LIPA, an enzyme that regulates the hydrolysis of $\mathrm{CE}$ and TAG, was significantly elevated in the spinal cords of SOD $1{ }^{\mathrm{G} 93 \mathrm{~A}}$ mice (Fig. $2 g$ ). Moreover, additional TAG metabolizing enzymes, including LIPE and LPL, were also significantly increased during ALS disease course (Fig. $2 h$ ). Notably, LPL mRNA levels were upregulated $>20$-fold in $\mathrm{ES}$ in SOD1 ${ }^{\mathrm{G} 93 \mathrm{~A}}$ mice. ALS patient samples showed significantly elevated LPL activity (Fig. 2i), which is consistent with our observation of increased TAG accumulation occurring in ALS patient samples. Collectively, these findings indicate neutral lipid accumulation in the spinal cords of ALS patients is not because of an aberrant increase in synthesis or a reduction in hydrolysis. Moreover, we speculate that disease-related reductions in SREBP2 and HMGCR and increases in LIPA may be a part of a compensatory response to lower lipid levels to mitigate lipid cacostasis, which is presumably a result of impaired intracellular or intercellular lipid trafficking. Notably, we also show that disease-related changes in cholesterol metabolism are detected in the feces, serum, and plasma of SOD $1^{\mathrm{G} 93 \mathrm{~A}}$ mice, thus supporting the tracking of cholesterol metabolites as potential disease biomarkers (Extended Data Fig. 26). Together, these results demonstrate that disease-associated $\mathrm{CE}$ and TAG accumulation in the spinal cord is neither driven by increased upstream SREBP2-mediated cholesterol biosynthesis nor by decreased CE or TAG hydrolysis.

\section{CE accumulation is associated with increased PC metabolism} Next, we sought to determine which CE synthesis pathways were upregulated during disease course. $\mathrm{CE}$ synthesis is dependent on CPLA2, which hydrolyzes PC to generate the fatty acids that are subsequently ligated to coenzyme A to synthesize acyl-CoA (Fig. $3 a$ ). Acyl-CoA cholesterol acyltransferase (SOAT1) then transfers the acyl group from acyl-CoA to cholesterol to generate $\mathrm{CE}$ (Akiba et al., 2003). In the spinal cords of SYMP and ES SOD ${ }^{\mathrm{G} 93 \mathrm{~A}}$ mice, mRNA levels for CPLA2 and SOAT1 were significantly upregulated twofold to fourfold (Fig. 3b). Furthermore, in the spinal cord GM of ALS patients, we detected almost a fourfold increase in cPLA2 enzymatic activity (Fig. 3c). Our work corroborates previous studies that showed increased cPLA2 staining in the spinal cords of SOD1 ${ }^{\text {G93A }}$ mice (Kiaei et al., 2005; Solomonov et al., 2016) and ALS 
a

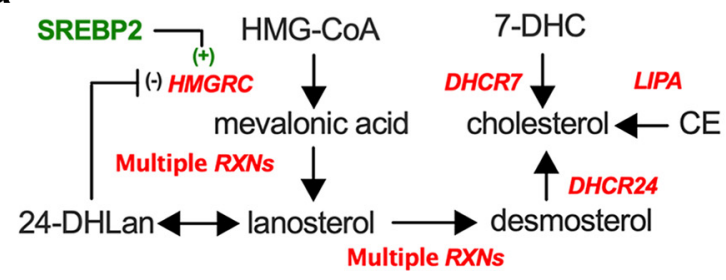

d

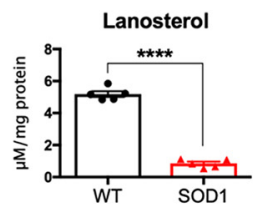

f

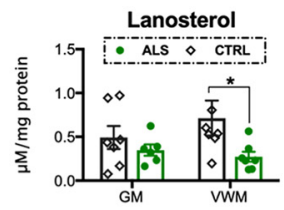

b
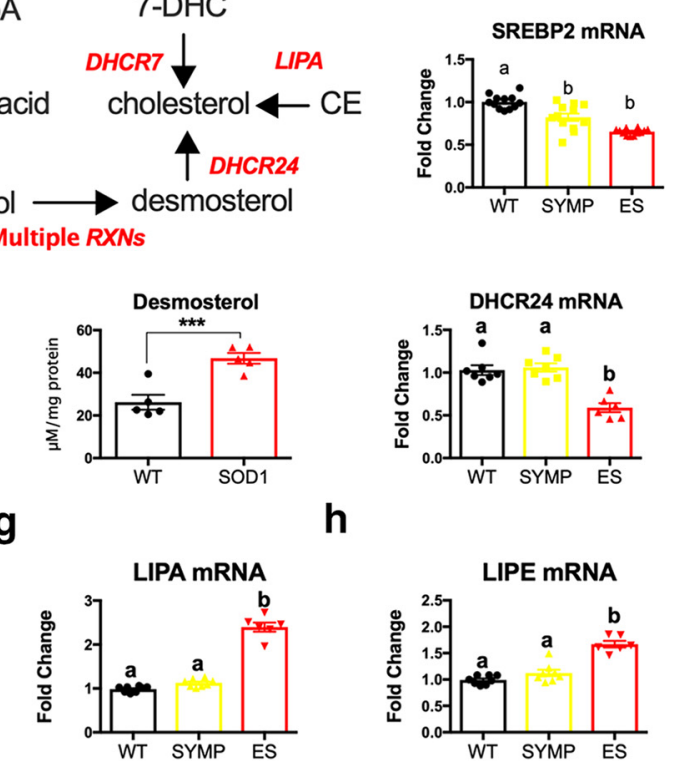

h
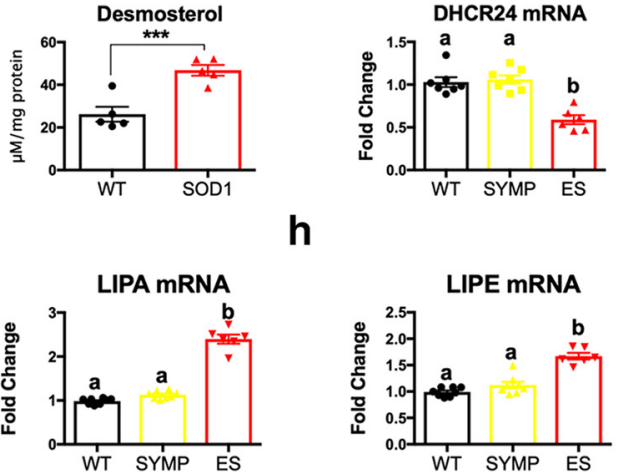

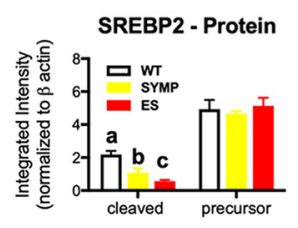

C
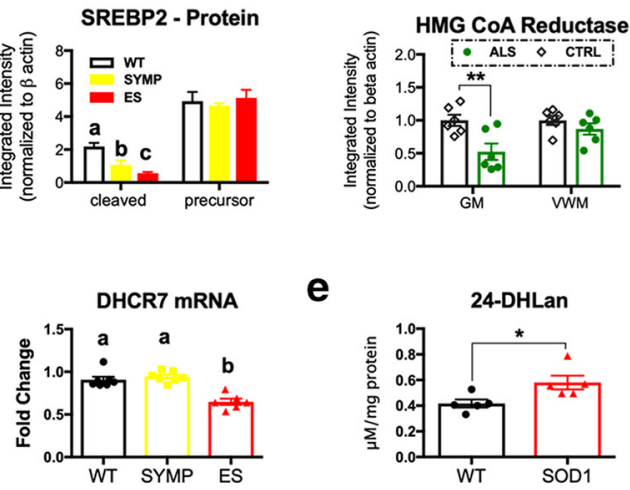

e
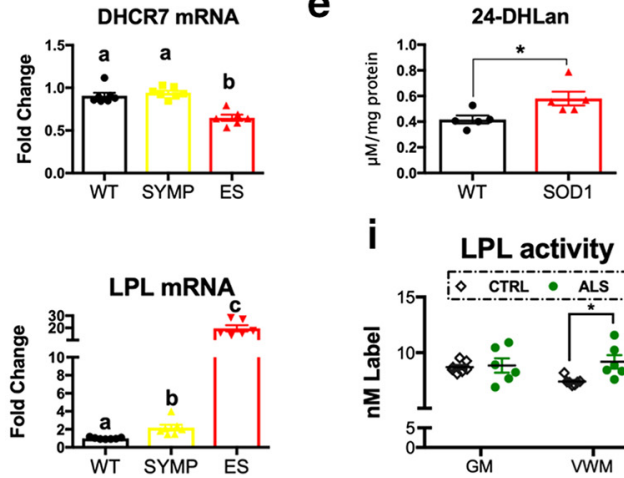

i

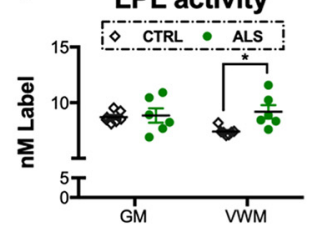

Figure 2. Lipid synthesis and hydrolysis are affected during ALS. $\boldsymbol{a}$, Metabolic pathways summarizing cholesterol metabolism. $\boldsymbol{b}$, SREBP2 mRNA and protein levels progressively decrease in the spinal cords of SYMP and ES SOD1 ${ }^{693 A}$ mice. $\boldsymbol{c}$, HMGRC protein levels are significantly reduced in the cervical spinal cord GM homogenates of ALS patients. $\boldsymbol{d}$, $\boldsymbol{e}$, Metabolic precursors of cholesterol (lanosterol, desmosterol, and 24DHLan) and the mRNA levels of enzymes (DHCR24, DHCR7) controlling their synthesis are significantly altered in SOD1 ${ }^{\text {G93A }}$ mice. $f$, Lanosterol levels are significantly reduced in the cervical spinal cord VWM homogenates of ALS patients. Enzymes that regulate CE and TAG hydrolysis are upregulated during disease. $\boldsymbol{g}$, LIPA, (h) LIPE and LPL mRNA levels are significantly increased in the spinal cords of $S O D 1^{G 93 A}$ mice. $\boldsymbol{i}$, LPL enzyme activity is significantly elevated in tissue homogenates of ALS patients. Statistical comparisons for patient data are relative to age-matched control (CTRL) tissue subtype, and SOD1 ${ }^{\text {G93A }}$ mice are compared with WT controls. ${ }^{* * *} p=0.0001 .{ }^{* * *} p=0.001$. ${ }^{* *} p=0.01$. ${ }^{*} p=0.05$. Columns not connected by the same letter are significantly $(p=0.001)$ different from each other. Error bars indicate SEM. Extended Data Figure 2-1 supports Figure 2. Extended Data Figure 2-1 shows SREBP2 Western blot data for Figure 26 . Extended Data Figure 2-2 shows SREBP2 levels in cervical spinal cord homogenates of ALS patients. Extended Data Figure 2-3 shows FC levels in the spinal cords of ALS patients. Extended Data Figure 2-4 shows, in SOD1 ${ }^{693 A}$ mice compared with controls, spinal cord levels of 24-dihydrolanosterol and desmosterol in ALS patients and controls. Extended Data Figure 2-5 shows expression levels of DGAT1 and DGAT2 in the spinal cords of SOD1 ${ }^{693 A}$ mice compared with controls. Extended Data Figure 2-6 shows disease-related changes in cholesterol analytes in the feces, serum, and plasma of $S O D 1^{693 A}$ mice.

patients (Shibata et al., 2010). Our findings suggest that cytosolic $\mathrm{CE}$ synthesis is enhanced during disease through an upregulation of cPLA2 and SOAT1.

Intracellular and intercellular CE mobilization is initiated when it is hydrolyzed by LIPA to regenerate FC, which is then transferred to lipoproteins through the activation of MTTP, ATP-binding cassette transporters ABCA1 and ABCG1, and caveolin-1,2 (CAV1, CAV2). The lipoprotein enzyme LCAT then regenerates $\mathrm{CE}$ by directly transferring an acyl group from $\mathrm{PC}$ to FC. In both SYMP and ES SOD $1{ }^{\mathrm{G} 93 \mathrm{~A}}$ mice, LCAT mRNA levels were significantly upregulated almost twofold in the spinal cord (Fig. $2 d$ ). Consistent with these observations, we also detected concomitant significant elevations (2- to 12-fold) in MTTP, ABCA1, ABCG1, CAV1, and CAV2 mRNA levels in SOD1 ${ }^{\mathrm{G} 93 A}$ mice (Fig. 3e). Moreover, we also observed almost a threefold increase in ABCA1 protein levels in the spinal cords of ES SOD $1^{\mathrm{G} 93 \mathrm{~A}}$ mice (Fig. 3f; Extended Data Fig. 3-1). Collectively, our results indicate that $\mathrm{CE}$ accumulation during ALS disease course is associated with an increase in PC catabolism.

\section{Lyso-PC is toxic to MNs}

Although CE generation reduces cellular exposure to highly reactive FC, CE synthesis through the CPLA2/SOAT1 and LCAT pathways results in a concomitant increase in Lyso-PC (Fig. $3 a$ ), a lipid with potent demyelinating properties (Ousman and David, 2000). Therefore, we measured SFA, MUFA, and PUFA Lyso-PC levels in ALS patient, SOD $1^{\mathrm{G} 93 \mathrm{~A}}$ mouse and in control spinal cord samples. In the spinal cord GM of sALS patients, a significant elevation in the $\mathrm{C}_{16}$ and $\mathrm{C}_{18: 1 \mathrm{n} 9}$ species of Lyso-PC was detected versus control samples (Fig. $3 g$ ). These results corroborate a recent mass spectrometry imaging study that showed
Lyso-PC accumulation in the spinal cords of ALS patients (Hanrieder and Ewing, 2014). We detected similar changes in Lyso-PC levels in the spinal cords of ES and MB SOD $1{ }^{\mathrm{G} 93 \mathrm{~A}}$ mice, specifically in the $\mathrm{C}_{16}, \mathrm{C}_{18}$, and $\mathrm{C}_{18 \text { :1n9 }}$ species (Fig. $3 h$ ). To determine whether Lyso-PC contributes to cellular demise in ALS, we assessed human $\mathrm{MN}$ viability after adding various concentrations $(0.0,0.1,1.0,3.0,10,30,100$, and $300 \mu \mathrm{M})$ of Lyso-PC isoforms $\left(\mathrm{C}_{16}, \mathrm{C}_{18}\right.$, and $\left.\mathrm{C}_{18: 1}\right)$ and fatty acid controls (palmitic acid, $\mathrm{C}_{16}$; steric acid, $\mathrm{C}_{18}$; oleic acid, $\mathrm{C}_{18: 1}$ ) to the culture media. Results from cell titer glow (CTG) and LDH viability assays showed that all three species of Lyso-PC were significantly toxic, with $\mathrm{C}_{16}$ being relatively more toxic than $\mathrm{C}_{18}$ and $\mathrm{C}_{18: 1}$ (Fig. 3i,j). Cell death as measured by CTG and LDH assays following the addition of the corresponding fatty acids to the culture media were no different from vehicle control (Fig. 3i,j). Our findings suggest that Lyso-PC, a byproduct of CE synthesis, accumulates in the spinal cords of ALS patients and in SOD $1^{\mathrm{G} 93 \mathrm{~A}}$ mice during disease, and that Lyso-PC is detrimental to $\mathrm{MN}$ survival.

\section{Neutral lipid accumulation in the CNS is sufficient to trigger an ALS phenotype}

The results of our in vitro studies suggest that neutral lipid accumulation leads to the generation of toxic Lyso-PC lipid species that contribute to the demise of human MNs. Finally, we wished to determine whether promoting spinal cord neutral lipid and Lyso-PC accumulation in normal mice was associated with $\mathrm{MN}$ death in vivo. To test this, we injected an AAV serotype 9 vector encoding a constitutively active (nuclear) form of SREBP2 (AAVSREBP2) into the CNS of WT mice at P0. Control mice were injected with an empty vector (AAV-null). Lumbar spinal cord 

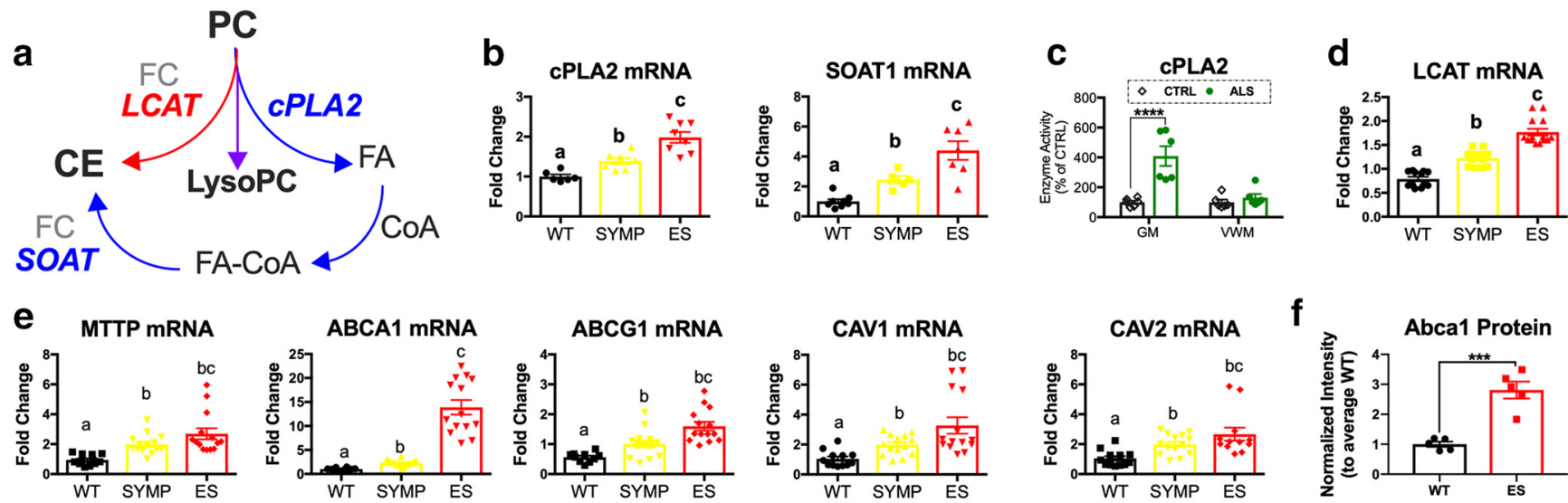

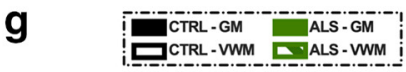

h

SFA LYSO - PC
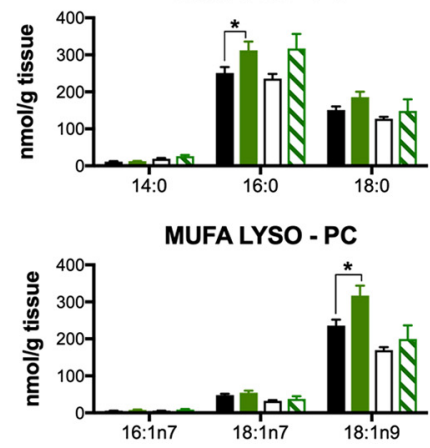

PUFA LYSO- PC

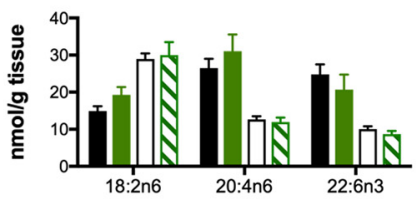

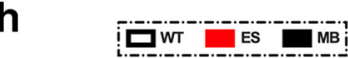

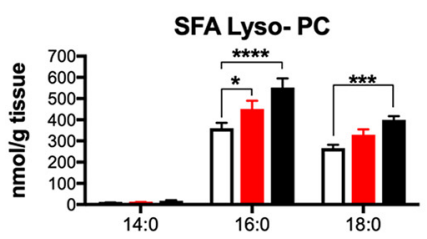

MUFA Lyso- PC

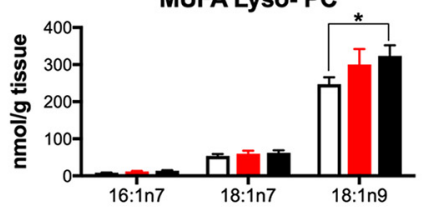

PUFA Lyso- PC

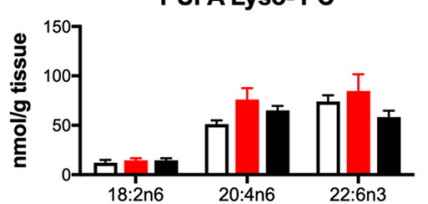

i

CTG Assay

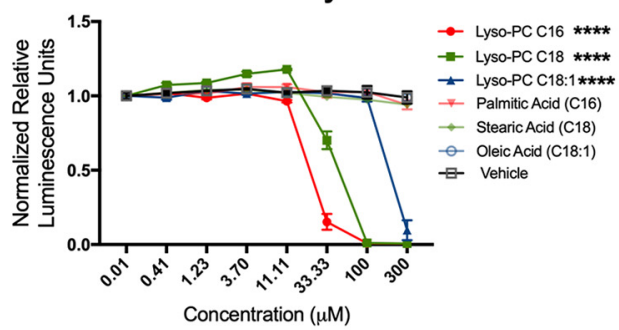

LDH Assay

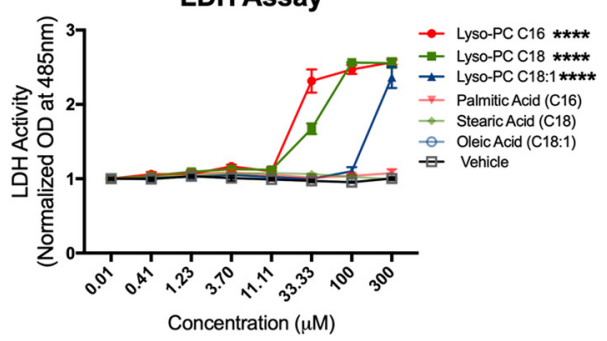

Figure 3. Cytosolic and lipoprotein $\mathrm{PC}$ metabolism contributes to CE synthesis and the accumulation of Lyso-PC, an inducer of MN death. $\boldsymbol{a}$, Metabolic pathways illustrating CE and Lyso-PC generation through the activation of CPLA2, cholesterol acyltransferase (SOAT1), and the lipoprotein enzyme LCAT. FA, Fatty acid. $\boldsymbol{b}$, CPLA2 and SOAT1 mRNA levels are significantly elevated in the spinal cords of SYMP and ES SOD1 ${ }^{693 A}$ mice. c, CPLA2 enzyme activity is significantly elevated in spinal cord GM tissue homogenates of ALS patients. $\boldsymbol{d}$, LCAT mRNA levels are significantly elevated in the spinal cords of SYMP and ES SODD ${ }^{193 A}$ mice. $\boldsymbol{e}$, The expression of ATP-binding cassette transporters (ABCA1, ABCG1), MTTP, and caveolin-1,2 (CAV1, CAV2) progressively increase in the lumbar spinal cords of SYMP and ES SOD1 ${ }^{693 A}$ mice. $\boldsymbol{f}$, ABCA1 protein levels are significantly higher in the lumbar spinal cord of ES SOD1 ${ }^{693 A}$ mice. $\boldsymbol{g}, \boldsymbol{h}$, Changes in SFA, MUFA, and PUFA species of Lyso-PC in cervical spinal cord homogenates (GM, VWM) of ALS patients, and in lumbar spinal cord tissue homogenates of ES and MB SOD1 ${ }^{G 93 A}$ mice. $i, j$, Lyso-PC significantly diminishes the viability of iPSC-derived human MNs in culture as assessed by the CTG and LDH assays. Lyso-PC C16 significantly $(* * * * 0=0.0001)$ different from vehicle at 33.33, 100, and 300 $\mu \mathrm{m}$ for CTG and LDH assays. Lyso-PC C18 significantly (**** $p=0.0001$ ) different from vehicle at 3.7, 11.11, 33.33, 100, and $300 \mu \mathrm{m}$ for CTG, and 33.33, 100 and $300 \mu \mathrm{m}$. Lyso-PC C18:1 significantly different from vehicle at $300 \mu \mathrm{m}$ for CTG and LDH assays. Statistical comparisons for patient data are relative to age-matched control (CTRL) tissue subtype and SOD1 ${ }^{693 A}$ mice are compared with WT controls. ${ }^{* * *} p=0.0001$. ${ }^{* * *} p=0.001$. ${ }^{*} p=0.05$. Columns not connected by the same letter are significantly $(p=0.001)$ different from each other. Error bars indicate SEM. Extended Data Figure 3-1 supports Figure 3 and shows Western blot data for Figure $3 f$.

levels of constitutively active SREBP2 were twofold higher in mice injected with AAV-SREBP2 than mice treated with AAV-null (Fig. $4 a$; Extended Data Fig. 4-1). Strikingly, AAV-SREBP2-injected mice developed progressive spasticity and hindlimb paralysis that resulted in a significantly reduced lifespan (median survival = 22 d; Fig. $4 a$ ). Mice injected with AAV-SREBP2 also displayed significant reductions in both lean and fat body mass compared with AAV-null mice (Fig. 4a). Importantly, large-diameter (30-50 $\mu \mathrm{m})$ and total $\mathrm{MN}$ cell counts (i.e., ChAT-positive cells) were also significantly reduced in AAV-SREBP2 versus AAV-null injected mice (Fig. 4a, b). Interestingly, increased GFAP staining, a marker of astrogliosis, was also found in the ventral spinal cord GM of AAVSREBP2 versus AAV-null-injected mice (Fig. 4b). As observed in ALS patients and SOD $1^{\mathrm{G} 93 \mathrm{~A}}$ mice, FC levels were unaltered in AAV-SREBP2-injected mice (Extended Data Fig. 4-2); however, SFA $\left(\mathrm{C}_{14}, \mathrm{C}_{16}, \mathrm{C}_{18}\right)$ and MUFA $\left(\mathrm{C}_{18: 1 \mathrm{n} 7}, \mathrm{C}_{18: 1 \mathrm{n} 9}\right)$ species of $\mathrm{CE}$ were significantly elevated up to eightfold (Fig. 4c). Furthermore, similar to ALS patients and SOD $1^{\text {G93A }}$ mice, several SFA, MUFA, and PUFA species of TAG and Lyso-PC were also significantly increased in the spinal cords of AAVSREBP2-injected mice (Fig. $4 d, e$ ). The results of this experiment indicate that inducing neutral lipid accumulation in the CNS is associated with neurodegeneration in vivo.

\section{Discussion}

More than 25 genes affecting a variety of cellular processes are associated with ALS (Peters et al., 2015). Why these various 
a
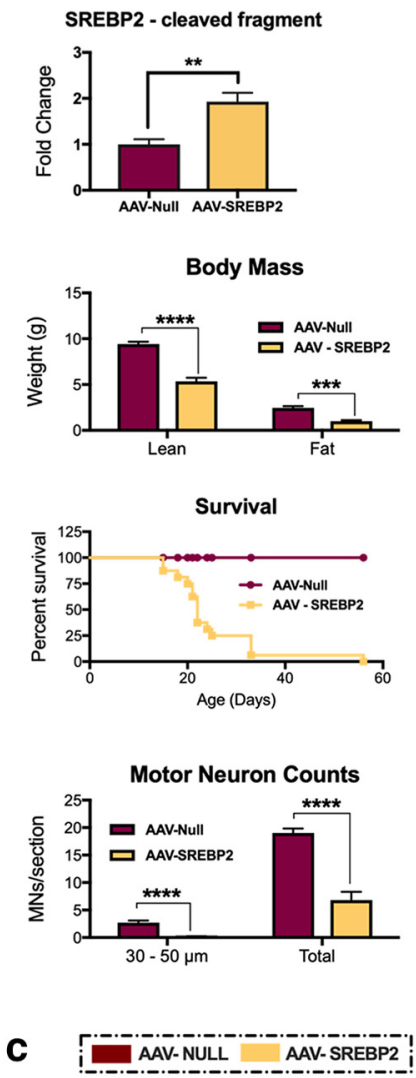

SFA Cholesterol Esters
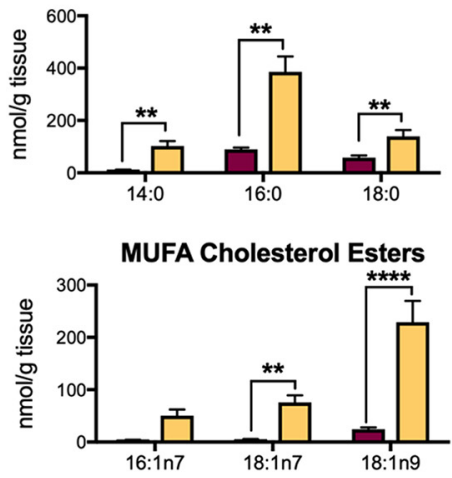

PUFA Cholesterol Esters

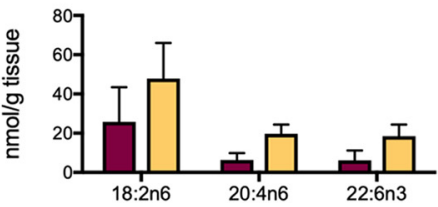

b

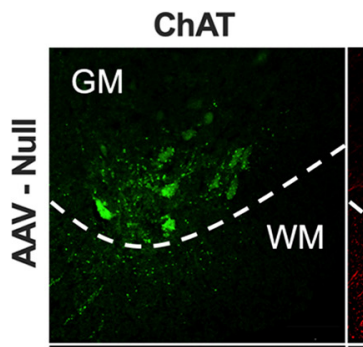

GFAP

DAPI
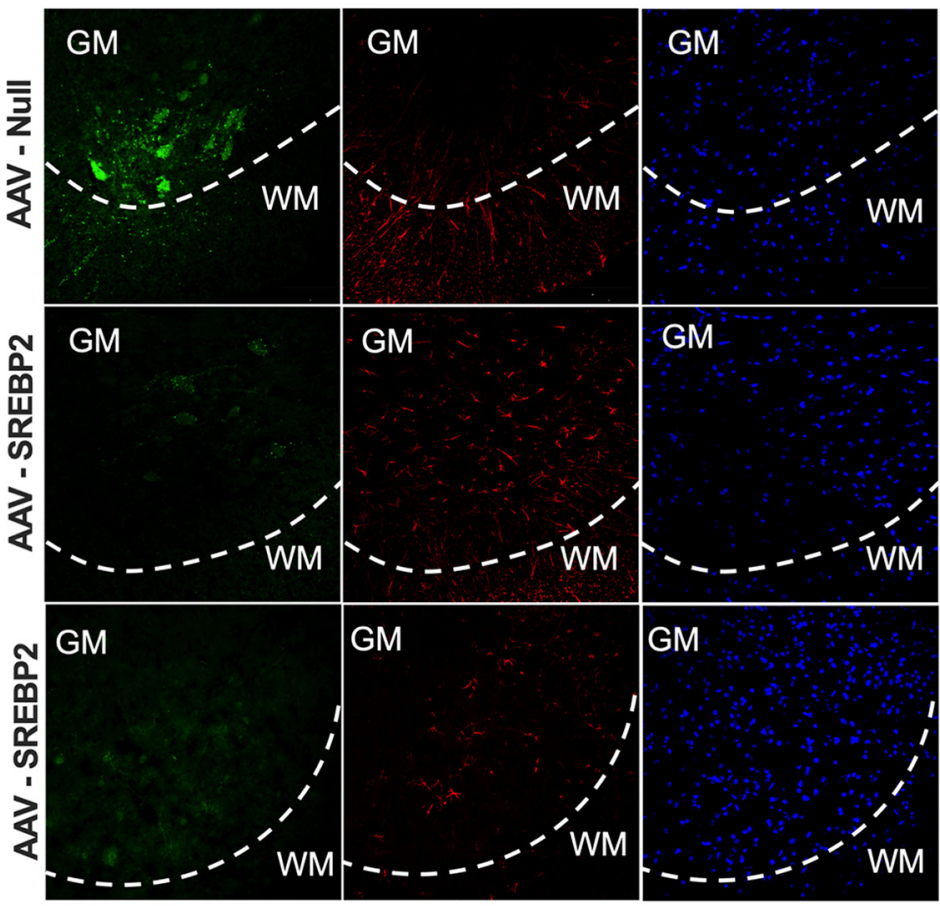

GM

e
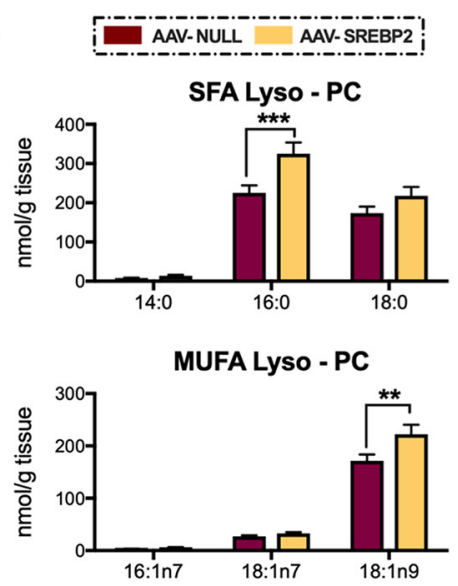

PUFA TAG
GM

GM

Merge

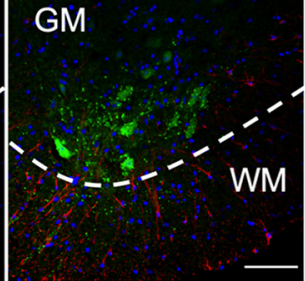

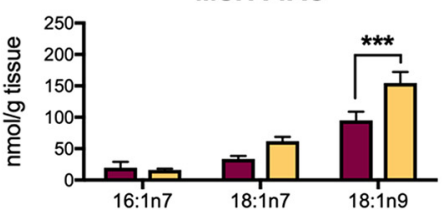

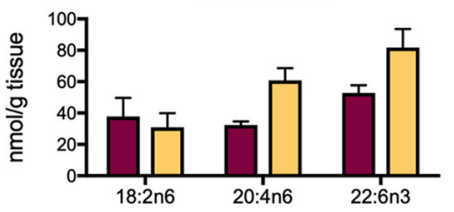

d

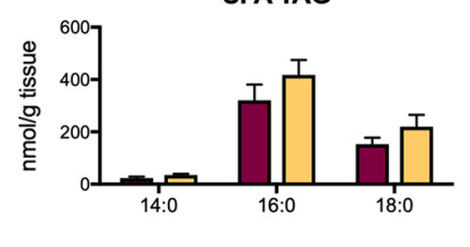

$T$

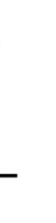

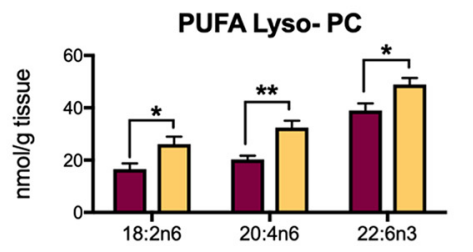

Figure 4. Increasing SREBP2 levels in the spinal cords of WT mice lead to neutral lipid accumulation and an ALS-like phenotype. $\boldsymbol{a}$, Cleaved SREBP2 protein levels in lumbar spinal cord tissue homogenates, mouse survival, body mass, and lumbar spinal cord MNs counts per section for large (30-50 $\mu \mathrm{m}$ diameter) and all MNs in mice injected with AAV-SREBP2 compared with littermates injected with AAV-null. $\boldsymbol{b}, 20 \times$ confocal images of ChAT and GFAP staining in the lumbar spinal cord of mice injected with AAV-SREBP2 compared with littermates injected with AAVnull. Scale bar, $100 \mu \mathrm{m}$. Lumbar spinal cord tissue homogenates levels of (c) CES, (d) triacylglycerides (TAG), and (e) Lyso-PC in WT mice following CNS injection of AAV-SREBP2 compared with littermates injected with AAV-null. ${ }^{* * *} p=0.0001$. ${ }^{* *} p=0.001 .{ }^{* *} p=0.01 .{ }^{*} p=0.05$. Error bars indicate SEM. Extended Data Figure 4-1 supports Figure 4. Extended Data Figure 4-1 shows Western blot data for Figure 4a. Extended Data Figure 4-2 shows FC levels in spinal cord tissue homogenates of AAV-SREBP2-injected mice compared with controls.

genetic mutations are exceedingly toxic to $\mathrm{MNs}$ remains unknown. For a number of human disorders, complex genetic and environmental interactions shape an individual's susceptibility to disease, age of disease onset, and rate of disease progression (Feinberg, 2007). Similar to neuropathic lysosomal storage diseases, we postulate that cellular variations in lipid composition and metabolism contribute to a tissue's relative vulnerability to disease (Dodge, 2017). For the spinal cord, its relatively high concentration in cholesterol may make it particularly susceptible to pathologic insults that result in disrupted lipid homeostasis 
(i.e., lipid cacostasis). Notably, several genes implicated in ALS (e.g., ANG, C9ORF72, HNRNPA1, SIGMAR1, SOD1, TARDBP, VAPB, VCP, ATXN2, and LXR) are modulators of lipid homeostasis (Moore and Riordan, 1990; Lastres-Becker et al., 2008; Chiang et al., 2010; Su et al., 2010; Morris et al., 2014; Yu et al., 2014; Li et al., 2015; Sanhueza et al., 2015; Tokutake et al., 2015; Mouzat et al., 2018; Liu and Wang, 2019). Here, we demonstrate that lipid cacostasis is a prominent feature of ALS and that its induction in WT mice is sufficient to trigger an ALS phenotype.

Sustained FC loading in mammalian cells leads to ER stress, ROS generation, mitochondrial dysfunction, a proinflammatory state, and activation of various cell death pathways (Rolo et al., 2004; Steck and Lange, 2010; Mutemberezi et al., 2016), all of which have been repeatedly implicated in the degeneration of MNs in ALS. Cellular toxicity is averted when excess FC is neutralized by its conjugation to fatty acids to form CEs (Steck and Lange, 2010). Indeed, our examination of ALS patient spinal cord samples showed that several SFA, MUFA, and PUFA species of CE were dramatically elevated, especially in the spinal cord GM. Similarly, we also detected significant progressive elevations in $\mathrm{CE}$ species in the spinal cords of SOD1 ${ }^{\mathrm{G} 93 \mathrm{~A}}$ mice. What drives CE accumulation in ALS remains unclear. Cholesterol forms complexes with a variety of lipids in disparate proportions and varying affinities. The strongest of these interactions are with long SFA species of glycosphingolipids, sphingomyelin, PC, and phosphatidylserine. Sterol complex formation with lipids with small polar head groups (e.g., phosphatidylethanolamine) or with MUFA and PUFA fatty acyl tails is less favored (Steck and Lange, 2010). Recently, we reported that glycosphingolipid accumulation is observed in the spinal cords of SOD ${ }^{\mathrm{G} 93 \mathrm{~A}}$ mice and ALS patients (Dodge et al., 2015), which in light of our current findings may be part of a compensatory response to sequester cholesterol. Notably, inhibition of glycosphingolipid synthesis exacerbates disease progression in SOD1 ${ }^{\mathrm{G} 93 \mathrm{~A}}$ mice (Dodge et al., 2015; Henriques et al., 2015). Previously, CE accumulation was suggested to be a consequence of sphingomyelin accumulation that also occurs during disease (Cutler et al., 2002). However, this seems unlikely because sphingomyelin depletion leads to enhanced CE synthesis (Stein et al., 1992). Moreover, a deficiency in sphingomyelin hydrolysis in the CNS is associated with FC rather than CE accumulation (Leventhal et al., 2001). Our current observations of increased cPLA2, SOAT1, and LCAT expression in SOD1 mice, elevated cPLA2 enzymatic activity in the spinal cords of ALS patients, and accumulation of Lyso-PC in the spinal cords of SOD ${ }^{\text {G93A }}$ mice and ALS patients suggest that CE deposition is driven in part through the transfer of acyl groups from PC to FC. Importantly, we also show that Lyso-PC, the byproduct of $\mathrm{CE}$ generation, is toxic to human MNs in vitro, thus suggesting that protracted esterification of cholesterol is detrimental to the neuromuscular system.

Cholesterol synthesis and metabolism is modulated by SREBP2 and LXRs. SREBP2 stimulates the transcription of genes to augment cellular cholesterol levels, whereas the activation of LXRs by oxysterols initiates the opposite effect (Quan et al., 2003; Steck and Lange, 2010; Mutemberezi et al., 2016). SREBP2 resides in the ER and is activated by sterol-poor conditions to undergo transport to the Golgi complex, where it undergoes proteolytic processing. The processed fragment enters the nucleus to activate the transcription of cholesterol biosynthetic genes, including HMGCR, the rate-limiting enzyme in cholesterol synthesis. The binding of cholesterol to SCAP, a Golgi escort protein, or the binding of oxysterols to INSIG, an ER anchor protein precludes the proteolytic processing of SREBP2 (Brown and Goldstein, 1997). We found a striking reduction $(\sim 75 \%)$ in the transcriptionally active form of SREBP2 in the spinal cords of SOD1 ${ }^{\mathrm{G} 93 \mathrm{~A}}$ mice. Disease-related changes in SREBP2 were not found in ALS patients; however, we did find that HMGCR protein levels were significantly reduced in the spinal cord GM of ALS patients. Consistent with these observations, we also observed that lanosterol, a metabolic precursor to cholesterol, was reduced in ALS patient and SOD $1^{\mathrm{G} 93 \mathrm{~A}}$ mouse spinal cord samples. Interestingly, lanosterol and other cholesterol metabolic precursors (24DHLan and desmosterol) were significantly elevated in the feces of SOD1 ${ }^{\mathrm{G} 93 \mathrm{~A}}$ mice. Disease-related changes in SREBP2, HMGCR, and cholesterol precursors are likely part of a compensatory response to further mitigate $\mathrm{CE}$ accumulation in the CNS. Collectively, these findings indicate that elevations in CE in ALS are not because of an aberrant increase in de novo cholesterol synthesis in the spinal cord, at least in the sporadic ALS patient tissue samples that we analyzed. However, this should be examined more closely in model systems of familial ALS (fALS) with disease-causing mutations in VCP and HNRNPA1, which regulate HMGCR degradation (Morris et al., 2014) alternative splicing, respectively (Yu et al., 2014). Our findings also have important implications for developing potential lipid-modulating therapies for ALS. For example, CNS penetrant statins are unlikely to provide added benefit to patients that already feature a downregulation of HMGCR in the spinal cord GM, as we observed in our current study. Indeed, sustained statin use will likely lead to unwarranted HMGCR inhibition in white matter, which is detrimental to myelination (Klopfleisch et al., 2008). Indeed, statin use in SOD ${ }^{\mathrm{G} 93 \mathrm{~A}}$ mice (Su et al., 2016) and in some ALS patients is associated with accelerated disease progression (Nefussy et al., 2011). The precipitating event that leads to an upregulation in CE generation remains unknown. Disrupted regulation of CE synthesis or FC trafficking may play a role. For example, ANG, another gene implicated in fALS, modulates CE synthesis (Moore and Riordan, 1990); whereas the fALS genes VAPB and SIGMAR1 play important roles in modulating intra-organelle lipid transport from the ER (Amarilio et al., 2005; Su et al., 2010). Furthermore, the cellular transport of SOD1 is dependent on its binding to various lipoproteins (Mondola et al., 2000), thus raising the possibility SOD1 may impact intercellular cholesterol trafficking between various CNS cell types.

Cholesterol accumulation inevitably leads to the accumulation of TAG, another neutral lipid. Indeed, we found that species of TAG were also increased in ALS patient SOD ${ }^{\text {G93A }}$ mouse spinal cord samples. Oil red $O$ staining, a marker of neutral lipids (i.e., CE and TAG) accumulation progressively increased the ependymal cell layer of the spinal cord central canal of SOD $1^{\mathrm{G} 93 \mathrm{~A}}$ mice. Intriguingly, similar Oil Red O pathology was reported in the spinal cord central canal of pigs and cattle with MN degeneration (O’Toole et al., 1994, 1995). Moreover, increased Oil Red O staining is also associated with $\mathrm{MN}$ death in wobbler (Andrews, 1975), $\mathrm{LXR}^{-1-}$ (Andersson et al., 2005), and A53T $\alpha$-synucleinexpressing mice (Giasson et al., 2002). It is unclear whether lipid accumulation contributes to neurodegeneration in these models or whether it is just a consequence. The results of our current experiments support the former explanation. Critically, we showed that increasing the expression of the transcriptionally active form of SREBP2, a key driver of cholesterol synthesis, in WT mice led to ALS-like lipid cacostasis in the spinal cord, astrogliosis, MN death, paralysis, and a reduced lifespan. Although we show that SREBP2 is not aberrantly activated during ALS disease course, the pathologic changes in spinal cord lipid composition 
(i.e., the accumulation of CE, TAG, and lyso-PC) that ensues after SREBP2 activation does mirror what occurs in SOD1 ${ }^{\mathrm{G} 93 \mathrm{~A}}$ mice and ALS patients. Moreover, our results also suggest that the rate or degree of lipid cacostasis (manifested as CE accumulation) may affect the rate of disease progression. For example, an eightfold increase in CE levels in AAV-SREBP2-treated mice is associated with a median lifespan of $22 \mathrm{~d}$, whereas a fourfold increase in CE is typically associated with a median lifespan of $122 \mathrm{~d}$ in SOD1 ${ }^{\mathrm{G} 93 \mathrm{~A}}$ mice in our laboratory. Furthermore, our detection of several disease-related changes in cholesterol analogs in the plasma and feces of SOD $1^{\mathrm{G} 93 \mathrm{~A}}$ mice may serve as potential biomarkers of ALS disease progression. Collectively, our results implicate neutral lipid cacostasis as a potential significant driver of $\mathrm{MN}$ demise; thus, we believe that restoring lipid homeostasis back to an optimal physiological state (i.e., eustasis) in the CNS is an attractive therapeutic strategy for the treatment of ALS.

\section{References}

Abdel-Khalik J, Yutuc E, Crick PJ, Gustafsson JA, Warner M, Roman G, Talbot K, Gray E, Griffiths WJ, Turner MR, Wang Y (2017) Defective cholesterol metabolism in amyotrophic lateral sclerosis. J Lipid Res 58:267-278.

Akiba S, Yoneda Y, Ohno S, Nemoto M, Sato T (2003) Oxidized LDL activates phospholipase A2 to supply fatty acids required for cholesterol esterification. J Lipid Res 44:1676-1685.

Amarilio R, Ramachandran S, Sabanay H, Lev S (2005) Differential regulation of endoplasmic reticulum structure through VAP-Nir protein interaction. J Biol Chem 280:5934-5944.

Andersson S, Gustafsson N, Warner M, Gustafsson JA (2005) Inactivation of liver $\mathrm{X}$ receptor beta leads to adult-onset motor neuron degeneration in male mice. Proc Natl Acad Sci USA 102:3857-3862.

Andrews JM (1975) The fine structure of the cervical spinal cord, ventral root and brachial nerves in the wobbler (wr) mouse. J Neuropathol Exp Neurol 34:12-27.

Baker DJ, Blackburn DJ, Keatinge M, Sokhi D, Viskaitis P, Heath PR, Ferraiuolo L, Kirby J, Shaw PJ (2015) Lysosomal and phagocytic activity is increased in astrocytes during disease progression in the SOD1 (G93A) mouse model of amyotrophic lateral sclerosis. Front Cell Neurosci 9:410.

Borchelt DR, Lee MK, Slunt HS, Guarnieri M, Xu ZS, Wong PC, Brown RH Jr, Price DL, Sisodia SS, Cleveland DW (1994) Superoxide dismutase 1 with mutations linked to familial amyotrophic lateral sclerosis possesses significant activity. Proc Natl Acad Sci USA 91:8292-8296.

Borchelt DR, Guarnieri M, Wong PC, Lee MK, Slunt HS, Xu ZS, Sisodia SS, Price DL, Cleveland DW (1995) Superoxide dismutase 1 subunits with mutations linked to familial amyotrophic lateral sclerosis do not affect WT subunit function. J Biol Chem 270:3234-3238.

Brown MS, Goldstein JL (1997) The SREBP pathway: regulation of cholesterol metabolism by proteolysis of a membrane-bound transcription factor. Cell 89:331-340.

Chaves-Filho AB, Pinto IF, Dantas LS, Xavier AM, Inague A, Faria RL, Medeiros MH, Glezer I, Yoshinaga MY, Miyamoto S (2019) Alterations in lipid metabolism of spinal cord linked to amyotrophic lateral sclerosis. Sci Rep 9:11642.

Chen X, Yazdani S, Piehl F, Magnusson PK, Fang F (2018) Polygenic link between blood lipids and amyotrophic lateral sclerosis. Neurobiol Aging 67:202.e1-202.e6.

Chiang PM, Ling J, Jeong YH, Price DL, Aja SM, Wong PC (2010) Deletion of TDP-43 down-regulates Tbc1d1, a gene linked to obesity, and alters body fat metabolism. Proc Natl Acad Sci USA 107:16320-16324.

Cutler RG, Pedersen WA, Camandola S, Rothstein JD, Mattson MP (2002) Evidence that accumulation of ceramides and cholesterol esters mediates oxidative stress-induced death of motor neurons in amyotrophic lateral sclerosis. Ann Neurol 52:448-457.

De Felice B, Santillo M, Seru R, Damiano S, Matrone G, Wilson RR, Mondola P (2004) Modulation of 3-hydroxy-3-methylglutaryl-CoA reductase gene expression by CuZn superoxide dismutase in human fibroblasts and HepG2 cells. Gene Expr 12:29-38.
Dodge JC (2017) Lipid involvement in neurodegenerative diseases of the motor system: insights from lysosomal storage diseases. Front Mol Neurosci 10:356.

Dodge JC, Treleaven CM, Pacheco J, Cooper S, Bao C, Abraham M, Cromwell M, Sardi SP, Chuang WL, Sidman RL, Cheng SH, Shihabuddin LS (2015) Glycosphingolipids are modulators of disease pathogenesis in amyotrophic lateral sclerosis. Proc Natl Acad Sci USA 112:8100-8105.

Dorst J, Kuhnlein P, Hendrich C, Kassubek J, Sperfeld AD, Ludolph AC (2011) Patients with elevated triglyceride and cholesterol serum levels have a prolonged survival in amyotrophic lateral sclerosis. J Neurol 258:613-617.

Dupuis L, Corcia P, Fergani A, Gonzalez De Aguilar JL, Bonnefont-Rousselot D, Bittar R, Seilhean D, Hauw JJ, Lacomblez L, Loeffler JP, Meininger V (2008) Dyslipidemia is a protective factor in amyotrophic lateral sclerosis. Neurology 70:1004-1009.

Feinberg AP (2007) Phenotypic plasticity and the epigenetics of human disease. Nature 447:433-440.

Giasson BI, Duda JE, Quinn SM, Zhang B, Trojanowski JQ, Lee VM (2002) Neuronal alpha-synucleinopathy with severe movement disorder in mice expressing A53T human alpha-synuclein. Neuron 34:521-533.

Hanrieder J, Ewing AG (2014) Spatial elucidation of spinal cord lipid and metabolite regulations in amyotrophic lateral sclerosis. Sci Rep 4:5266.

Henriques A, Croixmarie V, Priestman DA, Rosenbohm A, Dirrig-Grosch S, D'Ambra E, Huebecker M, Hussain G, Boursier-Neyret C, EchanizLaguna A, Ludolph AC, Platt FM, Walther B, Spedding M, Loeffler JP, Gonzalez De Aguilar JL (2015) Amyotrophic lateral sclerosis and denervation alter sphingolipids and up-regulate glucosylceramide synthase. Hum Mol Genet 24:7390-7405.

Horton JD, Shimomura I, Brown MS, Hammer RE, Goldstein JL, Shimano H (1998) Activation of cholesterol synthesis in preference to fatty acid synthesis in liver and adipose tissue of transgenic mice overproducing sterol regulatory element-binding protein-2. J Clin Invest 101:2331-2339.

Kiaei M, Kipiani K, Petri S, Choi DK, Chen J, Calingasan NY, Beal MF (2005) Integrative role of cPLA with COX-2 and the effect of non-steroidal anti-inflammatory drugs in a transgenic mouse model of amyotrophic lateral sclerosis. J Neurochem 93:403-411.

Klopfleisch S, Merkler D, Schmitz M, Kloppner S, Schedensack M, Jeserich G, Althaus HH, Bruck W (2008) Negative impact of statins on oligodendrocytes and myelin formation in vitro and in vivo. J Neurosci 28:1360913614 .

Lastres-Becker I, Brodesser S, Lutjohann D, Azizov M, Buchmann J, Hintermann E, Sandhoff K, Schurmann A, Nowock J, Auburger G (2008) Insulin receptor and lipid metabolism pathology in ataxin-2 knock-out mice. Hum Mol Genet 17:1465-1481.

Leventhal AR, Chen W, Tall AR, Tabas I (2001) Acid sphingomyelinase-deficient macrophages have defective cholesterol trafficking and efflux. J Biol Chem 276:44976-44983.

Li P, Ruan X, Yang L, Kiesewetter K, Zhao Y, Luo H, Chen Y, Gucek M, Zhu J, Cao H (2015) A liver-enriched long non-coding RNA, lncLSTR, regulates systemic lipid metabolism in mice. Cell Metab 21:455-467.

Liu Y, Wang J (2019) C9orf72-dependent lysosomal functions regulate epigenetic control of autophagy and lipid metabolism. Autophagy 15:913-914.

Mariosa D, Hammar N, Malmstrom H, Ingre C, Jungner I, Ye W, Fang F, Walldius G (2017) Blood biomarkers of carbohydrate, lipid, and apolipoprotein metabolisms and risk of amyotrophic lateral sclerosis: a more than 20-year follow-up of the Swedish AMORIS cohort. Ann Neurol 81:718-728.

Mondola P, Bifulco M, Seru R, Annella T, Ciriolo MR, Santillo M (2000) Presence of CuZn superoxide dismutase in human serum lipoproteins. FEBS Lett 467:57-60.

Mondola P, Seru R, Santillo M, Damiano S, Bifulco M, Laezza C, Formisano P, Rotilio G, Ciriolo MR (2002) Effect of $\mathrm{Cu}, \mathrm{Zn}$ superoxide dismutase on cholesterol metabolism in human hepatocarcinoma (HepG2) cells. Biochem Biophys Res Commun 295:603-609.

Moore F, Riordan JF (1990) Angiogenin activates phospholipase C and elicits a rapid incorporation of fatty acid into cholesterol esters in vascular smooth muscle cells. Biochemistry 29:228-233.

Morris LL, Hartman IZ, Jun DJ, Seemann J, DeBose-Boyd RA (2014) Sequential actions of the AAA-ATPase valosin-containing protein $(\mathrm{VCP}) / \mathrm{p} 97$ and the proteasome $19 \mathrm{~S}$ regulatory particle in sterol-accelerated, endoplasmic reticulum (ER)-associated degradation of 3-hydroxy3-methylglutaryl-coenzyme A reductase. J Biol Chem 289:19053-19066. 
Mouzat K, Molinari N, Kantar J, Polge A, Corcia P, Couratier P, Clavelou P, Juntas-Morales R, Pageot N, Lobaccaro JA, Raoul C, Lumbroso S, Camu W (2018) Liver X receptor gene variants modulate ALS phenotype. Mol Neurobiol 55:1959-1965.

Mutemberezi V, Guillemot-Legris O, Muccioli GG (2016) Oxysterols: from cholesterol metabolites to key mediators. Prog Lipid Res 64:152-169.

Nefussy B, Hirsch J, Cudkowicz ME, Drory VE (2011) Gender-based effect of statins on functional decline in amyotrophic lateral sclerosis. J Neurol Sci 300:23-27.

Nieweg K, Schaller H, Pfrieger FW (2009) Marked differences in cholesterol synthesis between neurons and glial cells from postnatal rats. J Neurochem 109:125-134.

O’Toole D, Ingram J, Welch V, Bardsley K, Haven T, Nunamaker C, Wells G (1994) An inherited lower motor neuron disease of pigs: clinical signs in two litters and pathology of an affected pig. J Vet Diagn Invest 6:62-71.

O’Toole D, McAllister MM, Griggs K (1995) Iatrogenic compressive lumbar myelopathy and radiculopathy in adult cattle following injection of an adjuvanted bacterin into loin muscle: histopathology and ultrastructure. J Vet Diagn Invest 7:237-244.

Ousman SS, David S (2000) Lysophosphatidylcholine induces rapid recruitment and activation of macrophages in the adult mouse spinal cord. Glia 30:92-104.

Parkinson GM, Dayas CV, Smith DW (2016) Perturbed cholesterol homeostasis in aging spinal cord. Neurobiol Aging 45:123-135.

Passini MA, Watson DJ, Vite CH, Landsburg DJ, Feigenbaum AL, Wolfe JH (2003) Intraventricular brain injection of adeno-associated virus type 1 (AAV1) in neonatal mice results in complementary patterns of neuronal transduction to AAV2 and total long-term correction of storage lesions in the brains of beta-glucuronidase-deficient mice. J Virol 77:7034-7040.

Peters OM, Ghasemi M, Brown RH Jr (2015) Emerging mechanisms of molecular pathology in ALS. J Clin Invest 125:2548.

Quan G, Xie C, Dietschy JM, Turley SD (2003) Ontogenesis and regulation of cholesterol metabolism in the central nervous system of the mouse. Brain Res Dev Brain Res 146:87-98.
Rabinowitz JE, Rolling F, Li C, Conrath H, Xiao W, Xiao X, Samulski RJ (2002) Cross-packaging of a single adeno-associated virus (AAV) type 2 vector genome into multiple AAV serotypes enables transduction with broad specificity. J Virol 76:791-801.

Rolo AP, Palmeira CM, Holy JM, Wallace KB (2004) Role of mitochondrial dysfunction in combined bile acid-induced cytotoxicity: the switch between apoptosis and necrosis. Toxicol Sci 79:196-204.

Sanhueza M, Chai A, Smith C, McCray BA, Simpson TI, Taylor JP, Pennetta G (2015) Network analyses reveal novel aspects of ALS pathogenesis. PLoS Genet 11:e1005107.

Shibata N, Kakita A, Takahashi H, Ihara Y, Nobukuni K, Fujimura H, Sakoda S, Kobayashi M (2010) Increased expression and activation of cytosolic phospholipase A2 in the spinal cord of patients with sporadic amyotrophic lateral sclerosis. Acta Neuropathol 119:345-354.

Solomonov Y, Hadad N, Levy R (2016) Reduction of cytosolic phospholipase A2alpha upregulation delays the onset of symptoms in SOD1G93A mouse model of amyotrophic lateral sclerosis. J Neuroinflammation 13:134.

Steck TL, Lange Y (2010) Cell cholesterol homeostasis: mediation by active cholesterol. Trends Cell Biol 20:680-687.

Stein O, Ben-Naim M, Dabach Y, Hollander G, Stein Y (1992) Modulation of sphingomyelinase-induced cholesterol esterification in fibroblasts, $\mathrm{CaCo} 2$ cells, macrophages and smooth muscle cells. Biochim Biophys Acta 1126: 291-297.

Su TP, Hayashi T, Maurice T, Buch S, Ruoho AE (2010) The sigma-1 receptor chaperone as an inter-organelle signaling modulator. Trends Pharmacol Sci 31:557-566.

Su XW, Nandar W, Neely EB, Simmons Z, Connor JR (2016) Statins accelerate disease progression and shorten survival in SOD1(G93A) mice. Muscle Nerve 54:284-291.

Tokutake Y, Gushima K, Miyazaki H, Shimosato T, Yonekura S (2015) ALSassociated P56S-VAPB mutation restrains 3T3-L1 preadipocyte differentiation. Biochem Biophys Res Commun 460:831-837.

Yu CY, Theusch E, Lo K, Mangravite LM, Naidoo D, Kutilova M, Medina MW (2014) HNRNPA1 regulates HMGCR alternative splicing and modulates cellular cholesterol metabolism. Hum Mol Genet 23:319-332. 